\title{
Prevalence of overweight and obesity among adolescents (13- 15 years) in Jorhat town
}

\author{
N. BAROOAH, M.S. BAROOAH AND N. NEOG
}

Received: 30.12.2013; Revised: 07.09.2014; Accepted: 21.09 .2014

See end of the paper for authors' affiliations

\section{N. BAROOAH}

Department of Food Science and Nutrition, Faculty of Home

Science, Assam Agricultural

University, JORHAT (ASSAM)

INDIA

Email: nimibarooah23@gmail.

com
ABSTRACT : The prime objective of the study was to assess the prevalence of overweight and obesity and thereby correlate it with life style factors of adolescents of Jorhat town, Assam. Body Mass Index $[\mathrm{BMI}]$ criteria was used to screen out the overweight and obese samples from 1007 adolescents belonging to seven High Schools of the town area. Standard techniques and structured, pre-tested schedules were used to elicit information on different parameters of the screened samples. The survey revealed the prevalence of overweight and obesity to be 4 per cent and 0.4 per cent, respectively. Percentage distribution of overweight and obesity according to gender showed 1.6 per cent and 0 per cent among boys and 2.6 per cent and 0.4 per cent among girls. Majority of overweight and obese were from the 15 years age group, the prime cause being physical inactivity. Positive association between BMI and fast food consumption was obtained for both boys $(\mathrm{r}=0.5422)$ and girls $(\mathrm{r}=0.0097)$. Boys spent an average of 17.5-19.5 hours in sedentary activities while girls spent more hours in sedentary activities (18-20 hours). Mean physical efficiency index (PEI) of boys ranged from 38.10-47.28 and that of girls ranged from 37.49-41.08 for different age groups, exhibiting a very poor physical efficiency. Correlation between BMI of screened samples and affluency also showed a positive association both for boys $(r=0.2748)$ and girls $(r=0.1758)$. Increasing prevalence of obesity in a population, particularly among children and adolescents is an early indicator of emerging health burden due to non-communicable diseases which needs to be addressed. Formulation of need based govt. and non-govt. programmes could help to provide appropriate measures to combat the menace along with school and college campaign focusing on allied aspects of overweight and obesity.

KEY WORDS: Overweight, Obesity, Prevalence, BMI, Life style factors

— HOW TO CITE THIS PAPER : Barooah, N., Barooah, M.S. and Neog, N. (2014). Prevalence of overweight and obesity among adolescents (13-15 years) in Jorhat town. Asian J. Home Sci., 9 (2) : 363-369. 